\title{
Quantitative Investigation of Particle Formation of a Model Pharmaceutical Formulation using Single Droplet Evaporation Experiments and X-Ray Tomography
}

\author{
Frederik J. S. Doerr ${ }^{\mathrm{a}, \mathrm{b}}$, Iain D. H. Oswald ${ }^{\mathrm{a}, \mathrm{b}}$, Alastair J. Florence Fl, $^{\mathrm{a}, *}$ \\ ${ }^{a}$ EPSRC CMAC Future Manufacturing Research Hub, Technology and Innovation Centre, 99 George Street, \\ Glasgow, G1 1RD, UK. \\ ${ }^{b}$ Strathclyde Institute of Pharmacy \& Biomedical Sciences (SIPBS), University of Strathclyde, Glasgow, \\ G4 ORE, UK.
}

\begin{abstract}
The implementation of a particle design platform that can be applied to novel pharmaceutical systems using acoustic levitation (SAL) and X-ray tomography (XRT) is discussed. Acoustic levitation was employed to provide a container-less particle design environment for single droplet evaporation experiments. Dried particles were subject to further visual and quantitative structural analysis using X-ray tomography to assess the three-dimensional volume space. The workflow of the combined SAL-XRT platform has been applied to investigate the impact of increasing HPMC K100LV concentrations on the evaporation, drying and final particle morphology of particles from a model pharmaceutical formulation containing metformin and D-mannitol. The morphology and internal structure of the formulated particles after drying are dominated by a crystalline core of D-mannitol partially suppressed with increasing HPMC K100LV additions. The final structure can be correlated to the observed evaporation kinetics. The characterisation of formulated metformin hydrochloride particles with increasing polymer content demonstrated the importance of an early-stage quantitative assessment of formulationrelated particle properties. The ability to study the evolution of solid phase formation
\end{abstract}

\footnotetext{
*Corresponding Author

Email address: alastair.florence@strath.ac.uk (Alastair J. Florence)

URL: www . cmac . ac .uk (Alastair J. Florence)
}

Preprint submitted to Advanced Powder Technology - WCPT8 Special Issue

September 11, 2018 
and its influence on the final particle morphology can enable the selection of process conditions that deliver the desired particle structure and consequent performance by design.

Keywords: Pharmaceutical Formulation Development, Single Droplet Evaporation, XRT Particle Structure Analysis, Crystallisation, Acoustic Levitation

\section{Introduction}

Spray Drying is a one-step continuous drying and isolation process broadly applied in the pharmaceutical and food industry to transform a liquid solution or primary particle suspension into a dry, solid powder.[1] Entering the drying chamber, the continuous flow is dispersed into a spray of droplets which are brought into contact with a dry hot gaseous flow. The complex evaporation and solidification processes are dominated by simultaneous transfer of heat, mass and momentum. The process conditions influence a number of particle properties including particle size, shape, morphology, porosity, density and mechanical stability.[2, 3, 4, 5] Spray Drying also has the potential to produce crystalline or amorphous materials as well as formulated systems which can be used to achieve drug formulations with distinct performance qualities. [6, 7, , , , , 10, 11, 12] The need for small-scale experimental platforms especially for continuous drying applications has previously been highlighted by academia and industry.[13] Systems for small scale droplet drying experiments allow the characterisation of the evaporation process for individual droplets and have been used to study the influence of the compound system and the process conditions on the attributes of the obtained final particles. Monitoring the evaporation and particle evolution enables the extraction of quantitative kinetic information that can support semi-empirical modelling of the drying process to inform development before moving to lab-scale. Groups have been using droplet drying experiments to investigate droplet shrinkage, [14] skin formation [15, 16, 17] and buckling phenomena of droplets undergoing drying. [18, 19] Acoustic levitation provides a containerless environment for single droplet evaporation experiments with a minimised 
risk for heterogeneous nucleation events and conductive heat transfer compared to similar experiments with individual droplets suspended on a filament. Quasi-stationary levitated droplets can be monitored to study liquid evaporation and particle formation processes. Applications utilising acoustic levitation to study single droplet evaporation or to perform single particle experiments of various compound systems have been reported in detail in the literature. [17, 20, 21, 22, 23, 24, 25, 26] The particles from such experiments can be assessed in terms of their critical solid state properties and performance. Optimisation of these particle properties through a deep understanding of the solid formation process is a key objective of particle engineering. Control or improvement of material-handling in the manufacturing process and the enhancment of product performance linked to attributes such as mechanical stability,[26] compressability,[27, 28] solubility[7, 29] and solid state stability [24] are just two potential areas of interest. Xray tomography (XRT) has been applied to a number of pharmaceutical systems for sample visualisation and/or to extract quantitative data on particle size, surface, shape and porosity. [30, 31, 32] XRT can be applied non-destructively to characterise a broad range of solid samples and is not limited to individual bulk or single particle properties. Importantly, the results of XRT analysis can be further related to the dynamics of the solidification process observed in the single droplet evaporation experiments. The goal of XRT analysis is increasingly moving towards relating structure to the dynamics of solidification.[16, 19]

In this paper we demonstrate the investigation of particle formation processes using an acoustic levitator (SAL) and the subsequent structural characterisation with XRT. The combined SAL-XRT platform can capture and quantify time-related effects such as evaporation kinetics, solid phase nucleation and drying rates as well as gives access to information on the final solid structure. The SAL uses optical and thermal imaging to monitor the evaporation process. [18, 22, 33] High-resolution XRT measurements enable to link the particle formation process to its final morphology and internal 
structure. This bespoke approach is applied to develop a single particle formulation for metformin hydrochloride (MET). As one of the World Health Organization's List of Essential Medicines, MET is widely used to treat non-insulin-dependent diabetes mellitus.[34] In solid form, metformin is commonly available as a highly water-soluble $\mathrm{HCl}$ salt and typically compressed into tablets for oral administration with high dose per tablet of $500 \mathrm{mg}$ to $1500 \mathrm{mg}$. The high drug load can cause problems during tableting and the short biological half-life commonly requires repeated adminstrations. [35, 36] A number of groups worked on formulated systems to produce MET-tablets with optimised compaction properties and/or dissolution properties to control the drug release profile. [28, 35, 36, 37, 38] Commercial derivatives of hydroxypropyl methylcellulose (HPMC) are frequently included in these oral controlled-release formulations and exist in various modifications and molecular sizes.[39] D-mannitol (MAN) is a common excipient for spray drying applications and can be used in formulations for diabetes mellitus treatment. MAN was added as a diluent to reduce the drug-load below $50 \mathrm{wt} \%$.

\section{Materials and methods}

\subsection{Chemicals / Samples}

MET and MAN were sourced from Sigma-Aldrich (St. Louis, USA). HPMC was kindly donated from Ashland (Benecel K100LV PH PRM, Covington, USA). Stock solutions were prepared at concentration of $300 \mathrm{mg} / \mathrm{mL}$ for MET, $150 \mathrm{mg} / \mathrm{mL}$ for MAN, and $10 \mathrm{mg} / \mathrm{mL}$ for HPMC. The composition of each used solution is listed in Table 1 Solution concentrations used for the drying experiments of pure and formualted systems were selected to achieve a comparable absolute solute mass enabling reliable imaging and levitation. All samples were prepared with filtered and de-ionised water (Milli-Q, Merck KGaA, Germany) and thoroughly mixed with a table vortex before usage. 


\subsection{Single Axis - Acoustic Levitator}

A single-axis acoustic levitator (SAL, Materials Development, Inc., Arlington Heights, USA) was used to perform containerless single droplet evaporation experiments (Fig. 1). The acoustic levitator has been described in detail elsewhere.[21] An additional custombuild electric incubation system (Okolab, Naples, Italy) was employed as an enclosure of the SAL to provide control over the surrounding temperature and humidity levels. The enclosure consists of heated walls and windows for both imaging systems. Nitrogen was used as a drying gas. The nitrogen was filtered and pre-heated before entering the chamber at $0.4 \mathrm{~L} / \mathrm{min}$. The temperature was kept constant and was constantly measured with a temperature and humidity sensor (AM2302, Adafruit Industries, USA) integrated in the enclosure. The measured relative humidity in all experiments was less than $2.5 \% \mathrm{RH}$. The average ambient temperature in the enclosure was $42.76 \pm 0.15{ }^{\circ} \mathrm{C}$. Prior to any experiments, the system was given a warm-up period of at least one hour to reach stable conditions monitored in terms of humidity, temperature and the generated acoustic signal.

In order to characterise the droplet evaporation process, each experiment was monitored utilising a Fastcam SA1.1 high speed camera (Photron, Tokyo, Japan) and an A6702sc thermal camera (FLIR Systems Inc., Wilsonville, USA). Images from the live stream of the high speed camera were collected at $1 \mathrm{fps}$. The images were used to monitor the evaporation process and to detect the onset of solid phase formation. During acoustic levitation, the droplet is deformed into an oblate spheroid. The volume and surface area were calculated from the major and minor axis using an ellipse fitting method for each image of the 2D droplet projection. The evaporation mass flux $(\dot{m})$ was calculated iteratively from the changing droplet volume over time and is expressed in relation to the available droplet surface area. Here, the initial point of skin formation at the droplet lockpoint (LP) is defined by a discontinuous change of the mass flux at the final inflection point of the droplet volume curve before reaching a constant end- 
volume. Thermal images were used to extract surface temperature information from the droplets and particles after reaching LP. The recorded surface temperature information can be used to identify the state of liquid evaporation at wet bulb temperature and characterise the particle surface heating kinetics after skin formation until reaching a stable end-temperature for the dried particle.[22, 33] The droplet surface temperature information from thermal imaging were corrected with an emissivity factor of 0.96 for water.[33] Following LP, the thermal emission can change depending on the characteristic thermal radiation emitted from the solid phase composition. Therefore, the thermal emissivity factor for each solid phase composition was estimated from the recorded temperature of the particle surface after reaching a constant end-temperature level $\left(\mathrm{T}_{\text {Dry }}\right)$ and the corresponding recorded ambient temperature $\left(T_{\infty}\right)$. The applied thermal emissivity correction factors $(\varepsilon)$ for each tested composition are listed in Table 5 (see ESI).

\subsection{X-ray Tomography and XRT Image Analysis}

A SKYSCAN 2211 X-ray tomograph (NanoCT, Bruker, Kontich, Belgium) with conebeam arrangement was employed for this project. The samples were scanned with an image pixel size of $1.2 \mu \mathrm{m}-1.8 \mu \mathrm{m}$, frame averaging of 4 and a rotation step size of $0.2^{\circ}$. The X-ray acceleration voltage was set to $40 \mathrm{keV}$. A reference scan was collected at the end of each run to enhance post-alignment and compensate for potential shifts during the scan. Image reconstruction was performed using SkyScan NRecon with InstaRecon (version 1.7.1.6, Bruker, Kontich, Belgium).

XRT image processing was carried out with custom scripts developed in MATLAB (MathWorks, USA). Images of each processing stage are displayed in Fig. 2. Individual reconstructed images were pre-processed using an edge-preserving image filter (anisotropic diffusion [40, 41]) or local low-contrast smoothing in case of HPMC to reduce random noise and prepare the images for subsequent binarisation (Fig. 2 a). The binarisation was performed with a histrogram-based algoritm [42] or optimised manually. Ultimately, remaining noise was removed using a size threshold of 10 voxel for 
black and white speckles and a 3D volume connectivity detection algorithm to remove non-connected binary volumes. The pre-processed and binarised images yielded the detected solid phase volume (V, Fig. 2 b). An additional 3D-morphological closing operation with a subsequent enclosed background filter and an integrated feedback-loop on detected internal background volumes was applied to define a region of interest for the particle solid phase volume (V_ROI, Fig. 2 c). Extracted information of each particle are descriptors of the particle shape and its volume distribution. The absolute particle solid phase can be quantified directly from V (Fig. 2 b). The particle porosity $\left(\Delta \mathrm{V} \_\right.$ROI, Fig. 2 d) can be calculated from a simple subtraction of $\mathrm{V}$ from V_ROI. In order to quantify concave surface volumes ( $\Delta$ V_ROI_CH, Fig. 2 2 e) as a descriptor for particle surface buckling, V_ROI was subtracted from the volume space of a 3D convex hull around V_ROI.[43] The detected volumes were related to the maximum particle space represented by a sphere with equivalent maximum Feret diameter $\left(\mathrm{V}_{\text {eqSph,Feret }}\right)$ to counter the impact of deviations in the inital droplet volume on the detected particle volume fractions. For visualisation, image stacks were imported in CTVox (version 3.2.0, Bruker, Kontich, Belgium).

\section{Results and Discussion}

\subsection{Solidification and Skin Formation of HPMC and formulated Systems of MET}

Single droplet experiments of a HPMC solution with a starting concentration of $10 \mathrm{mg} / \mathrm{mL}$ (HPMC_10, Table 1] were performed in comparison to pure water. Fig. 3 shows the recorded normalised droplet diameter and droplet surface temperature of the evaporating HPMC solution in direct comparison to pure water. Over the course of SAL experiment, the liquid evaporation rate of HPMC droplets increasingly deviates from the evaporation of pure water. The lockpoint (LP) due to polymer skin formation is detected after $179.79 \pm 12.93 \mathrm{~s} / \mathrm{mm}^{2}$. After the initial skin formation the rate of water evaporation of HPMC_10 droplets is further reduced. The permeation and evaporation 
of additional water through the polymeric surface layer leads to a radial pressure gradient that causes a collapse of the particle surface inside the droplet core (SC) and the formation of a vacuole. The generated surface enhances the evaporation of the remaining moisture which causes a two-step transition to the end-temperature level as shown in the recorded surface temperature curve after LP. Pure water droplets do not display a discontinuous reduction in the evaporation kinetics as observed for droplets of HPMC. The final mean diameter of six water droplet evaporation experiments was $345.43 \mu \mathrm{m}$. Below that size a levitation of the droplets with the SAL set-up was not stable due to secondary acoustic reflections from the enclosure.

Subsequent to the single droplet evaporation experiments, each HPMC particle was collected and analysed using XRT to quantify the solid phase volume and extract other structural descriptors on size, shape and particle porosity (Section 3.2). The solid phase volume of the particles and the solid phase mass can be used to determine the solid phase true density (Equation 11. The solid phase mass is derived from the starting solute concentration $\left(c_{0}\right)$ and the initial droplet volume $\left(V_{\text {Droplet }, 0}\right)$. The solid phase volume $\left(V_{C T}\right)$ can be directly quantified from the XRT image data.

$$
\rho=\frac{m}{V}=\frac{c_{0} \cdot V_{\text {Droplet }, 0}}{V_{C T}}
$$

To approximate the HPMC diffusion coefficient in water, it is assumed that there is no internal mixing and that the surface concentration of HPMC $\left(c_{s}\right)$ reaches solid true density at LP ( $\rho=\rho_{\text {crit }}=c_{s}$ ) by solving Equation 2 for a diffusion controlled surface enrichment $(E)$ during steady-state evaporation in accordance with the d2-law (Equation 3] for Péclet numbers (Pe) below 20.[44, 45]

$$
E=\frac{c_{s}}{c_{m}}=1+\frac{\mathrm{Pe}}{5}+\frac{\mathrm{Pe}^{2}}{100}+\frac{\mathrm{Pe}^{3}}{4000} \quad \text { with } \quad \mathrm{Pe}=\frac{\kappa}{8 \cdot D_{s}}
$$




$$
d^{2}(t)=d_{0}^{2}-\kappa \cdot t
$$

The mean solute concentration of the droplet $\left(c_{m}\right)$ can be determined from the starting concentration of the solution and the observed absolute change in the droplet volume at LP. The calculated solid true density $\left(\rho_{\text {crit }}\right)$ and diffusion coefficient $\left(D_{s}\right)$ from three individual single droplet experiments are listed in Table $2, \rho_{\text {crit }}$ of HPMC was calculated to be $1.36 \pm 0.02 \mathrm{~g} / \mathrm{cm}^{3}$ which is in agreement with data available from literature for other HPMC derivatives of $1.33 \mathrm{~g} / \mathrm{cm}^{3}$.[46] Solving Equation 2 for each experiment yields an approximated diffusion coefficient for HPMC in water of $4.61 \mathrm{E}-11 \pm 0.26 \mathrm{E}-11 \mathrm{~m}^{2} / \mathrm{s}$ at a LP surface temperature of $29.18 \pm 1.01{ }^{\circ} \mathrm{C}$ with an evaporation rate $(\kappa)$ of $5487.10 \pm 137.76 \mu \mathrm{m}^{2} / \mathrm{s}$ and Pe of $14.92 \pm 1.23$. The approximated diffusion coefficient of HPMC in water is significantly lower than the diffusion coefficients of MET and MAN reported in literature of $7.56 \mathrm{E}-10 \mathrm{~m}^{2} / \mathrm{s}\left(29.18{ }^{\circ} \mathrm{C}\right.$, calculated see Fig. 10 (see ESI)) and $1.17 \mathrm{E}-09 \mathrm{~m}^{2} / \mathrm{s}$ $\left(37^{\circ} \mathrm{C}\right)$, respectively.[47, 48, 49] According to Equation 2, smaller diffusion coefficients will lead to an increase in surface enrichment. This indicates that HPMC is expected to predominately solidify as part of the particle surface layer during skin formation at LP. The comparatively high diffusion coefficients of MET and MAN allow both small organic compounds to compensate part of their radial concentration profile caused by liquid evaporation on the droplet surface. Therefore, MET and MAN would be expected to predominantly solidify as part of the particle core.

The evaporation and drying of formulations of MET with MAN and HPMC (MS_0 MS_4, Table 1) were investigated in a series of single droplet drying experiments with starting volumes of $9.93 \pm 1.15 \mu \mathrm{L}$ using the SAL. Fig. 4 shows the results for three selected formulations (MS_0, no HPMC; MS_1, low HPMC; MS_4, high HPMC). The results indicate that the addition of HPMC significantly influences the kinetics of liquid evaporation and particle drying after solid skin formation (LP) even at relative mass concentrations of HPMC less than $1 \mathrm{wt} \%$ as in the case of MS_1. The impact of HPMC 
can be observed most dominantly during the phase of liquid evaporation with a reduced evaporation rate and, subsequently, in a delay in the initial solid phase nucleation. The reduced evaporation of water from the droplet surface in MS_1 and MS_4 leads to an increased droplet surface temperature during liquid evaporation compared to MS_0. The delay of LP can be observed for solutions with additions of HPMC of up to $4.5 \mathrm{mg} / \mathrm{mL}$ (MS_4) compared to MS_0 despite a higher total solute starting concentration.

Fig. 5 shows the derived liquid evaporation mass flux and the heating rate of the particle surface during drying for the single droplet evaporation experiments presented in Fig. 4 The droplet evaporation mass flux is calculated iteratively from the change in droplet volume over time and normed using the available surface area. After LP, the evaporation mass flux cannot be further tracked using a shape-based analysis of the image data and, therefore, is set transparent in Fig. 5 The experienced maximum mass flux $\left(\dot{m}_{\max }\right)$ and maximum heating rate $\left(\dot{T}_{\max }\right)$ for single droplet experiments of HPMC and MET formulations are listed in Table 3 . The maximum heating rate is the first time-derivative of the surface temperature profile at the point of inflection undergoing a transition from the wetbulb temperature to the final constant temperature corresponding to the ambient temperature $\left(T_{D r y}=T_{\infty}\right)$. The results indicate that the evaporation flux across the droplet surface is significantly reduced for droplets with additions of HPMC and is further reduced for increasing HPMC starting concentrations. The reduction of water mass transfer prior to reaching LP supports the previous considerations of HPMC surface enrichment with an impact on the overall water surface permeability and evaporation. In all cases, the evaporation flux increases over time before reaching a maximum and a subsequent discontinuous reduction due to solid skin formation at LP. The drying rates of the particles after LP are equally reduced with increasing HPMC concentrations which indicates decelerated mass transfer of remaining moisture to the particle surface leading to lower drying kinetics. This could be caused by a reduction in the water permeability through the particle surface layers due to an increasing thick- 
ness of the polymer skin around the particle. The maximum drying rates are limited by the accessible drying temperatures that can be applied in combination with the current SAL setup. Work to extend this method to encompass temperature regimes that more closely mimic those experienced across the full range of drying platforms of industrial relevance is ongoing.

\subsection{Particle Morphology Characterisation using XRT}

Particles from single droplet experiments were subject to a further in-depth structural characterisation using XRT. Fig. 6 shows the resulting particle morphologies within the investigated particle design space during the evaporation process (SAL Image Data) and after characterisation with XRT (XRT Image Data), respectively.

The SAL Image Data depict the moment of LP detection (top) and of the final dried particle (bottom) for each compound (Fig. 61-3) as well as for five formulations of MET with changing additions of HPMC (Fig. 64 a-e, MS_0 - MS_4). The SAL images allow a first visual, qualitative assessment of the final particle characteristics as they evolve over time. Pure solutions of MET (Fig. 61, MET_75) and MAN (Fig. 62, MAN_75) solidify as highly crystalline particles with emerging crystalline solid phase obscuring the light transmissive droplet center at LP. In contrast, MS_0 (Fig. 664 a) with a combination of equal concentrations of MET and MAN reaches LP without the visual appearance of large structured solid primary particles. Here, the obscuration of the droplet center occurs post-LP at elevated temperatures before reaching a fully dried state indicating a temporary suppression of crystal nucleation for this system. This effect is further enhanced with increasing polymer additions and several polymers including HPMC have been shown to inhibit crystal nucleation and/or growth, although the mechanisms are not well understood.[50] Whilst beyond the scope of this study, the SAL-XRT platform does provide a convenient means to systematically investigate both the onset of nucleation and the resultant difference in internal particle microstructure for different polymer and solute formulations. 
The XRT Image Data are volume rendered visualisations of the 3D image space after binarisation and are also included in Fig. 6 to show the particle morphology (top) as well as the internal particle structure (bottom). Details of the internal structure for three selected particles are displayed in Fig. 7 (a - MAN_75, b - MS_0 and c - MS_4). MET shows large block-like solids that are agglomerated to form dense, flattened particles (Fig. 61). MAN particles are highly spherical and highly porous (Fig. 6]2, details see Fig. 7]a). The particles consist of large rod-shaped crystalline primary solids. The obtained MAN particles have a similar internal structure as reported for MAN particles from co-current spray drying at reduced evaporation kinetics using an inlet temperature of $65^{\circ} \mathrm{C}$ and from counter-current spray drying with extended drying times. [51, 52] HPMC particles have smooth surfaces and large inner voids (Fig. 63). This morphology has been reported previously in the literature for other large molecules such as glycoproteins at large Péclet numbers of 5.6 and 16.8.[3]

The XRT Image Data for formulated particles of MET with MAN and HPMC (MS_0 - MS_4) are displayed in Fig. 64 a-e and demonstrate the impact of both excipients on the final particle morphology. The direct comparison indicates a qualitative change in the overall particle morphology from near sphericity to highly buckled particles with increasing HPMC concentrations. The observed inner particle structure suggests that the extent and size of the internal crystal core is reduced for increasing HPMC solid mass concentrations most significantly for HPMC solid mass of 5.66 wt\% (MS_3) and $10.71 \mathrm{wt} \%$ (MS_4). At decreasing solid mass concentrations of HPMC below $1.96 \mathrm{wt} \%$ (MS_2), the rod-like crystal habit of MAN, as identified in particles from pure MAN solution (MAN_75, Fig. 7 a), creates an inner particle structure that supports the overall spherical morphology of the particle. This reduction in size of the rod-shaped primary solids as part of the crystalline particle core further correlates with a decline in the particle porosity for increasing HPMC concentrations. The drastic size reduction of the primary, rod-shaped solids within the crystalline particle core and its impact on 
the final particle porosity are best visualised in a direct comparison for two selected particles without the addition of HPMC (MS_0) and with a HPMC solid mass ratio of 10.71 wt\% (MS_4) shown in detail in Fig. 7 b and c, respectively.

The impact of the polymer on the particle morphology and internal microstructure can be quantified using descriptors for particle size, shape and porosity. Fig. 8 (bottom) shows the detected volumes for the primary solid phase $(\mathrm{V}$, white), the particle porosity $\left(\Delta V \_R O I\right.$, blue $)$ and the detected concave surface volumes $\left(\Delta V \_R O I \_C H\right.$, red) for a single cross-section of the XRT image stack from each tested formulated system (MS_0 - MS_4). In Fig. 9 the extracted quantified volumes for V, $\Delta \mathrm{V} \_$ROI and $\Delta \mathrm{V} \_$ROI_CH are normalised against the volume of a sphere with equivalent maximum Feret diameter $\left(\mathrm{V}_{\text {eqSph,Feret }}\right)$ and correlated with the HPMC starting concentration. The data support the initial visual observations for formulated MET particles with a reduction in the particle porosity fraction of $83.59 \%$ between MS_0 and MS_4. Detected concave surface volume fractions ( $\Delta \mathrm{V} \_$ROI_CH) are proportionally higher for pure MET-MAN (MS_0) particles compared to systems with additions of HPMC below $1.96 \mathrm{wt} \%$ as in case of MS_1 and MS_2. This initial over-proportional decrease of $\Delta \mathrm{V} \_$ROI_CH at low HPMC concentrations can be related to a substantial changes in the particle surface roughness. Here the polymer leads to a reduction in local crystal growth most dominantly expressed in the particle surface layers. For higher HPMC concentrations, $\Delta \mathrm{V} \_$ROI_CH rises from its minimum of $1.11 \pm 0.41 \%$ for MS $\_1$ to $6.16 \pm 1.50 \%$ for MS_4 as a result of increasingly strong particle surface buckling with large concave volumes.

In order to quantify the influence of the drug formulation on the overall particle morphology, descriptors for the particle shape were extracted from the XRT data (Table 4). The particle sphericity was calculated as a function of V_ROI and its surface area using a definition by Wadell.[53] Additionally, an aspect ratio of each particle was determined from the major and minor characteristic axes of an ellipsoidal fit with the same normal- 
ized second central moment as V_ROI. The extracted quantitative shape descriptors reflect the visual impression of increased particle deformation and surface buckling with rising concentrations of HPMC. Particles from a solution of MET and MAN without the addition of HPMC (MS_0) exhibit the smallest aspect ratio with $1.20 \pm 0.05$ and highest sphericity of $0.95 \pm 0.04$. For formulations with HPMC (MS_1 - MS_4), the aspect ratio and sphericity are in strong correlation with the amount of added HPMC. Changes in the shape are most pronounced in particles with HPMC starting concentrations of $0.75 \mathrm{mg} / \mathrm{mL}$ (MS_3) and $2.25 \mathrm{mg} / \mathrm{mL}$ (MS_4). This supports the detected increase in surface buckling for formulations with higher HPMC solid mass ratios since the generated additional particle surface and the reduced V_ROI are both directly used to calculate the particle sphericity as defined by Wadell. The high deformations and surface buckling effects of particles with HPMC solid mass ratios of $5.66 \mathrm{wt} \%$ and $10.71 \mathrm{wt} \%$ could potentially decrease particle flowability and, therefore, manufacturability in the downstream process. The implemented XRT image analysis capabilities are a valuable extension of an initial qualitative visual interpretation and offer the opportunity to quantify key particle properties including particle size, shape and internal microstructure. The evaluation of these particle descriptors showed a strong correlation of the particle structure to its formation process monitored on the SAL. The non-destructive nature of the presented XRT methodologies enable a further assessment of the particle performance characteristics i.e. undergoing dissolution or during compaction. Whilst not explored here, these extensions of capability to 3D structure, provides a basis for future work to develop structure-property relationships.

\section{Conclusions}

The reported SAL-XRT platform allows the direct measurement of single droplet drying kinetics and the resultant particle structure as a function of solution composition. The combined characterisation links the solid formation process to a 3D quantitative investi- 
gation of the particle. The capabilities of this platform and the developed methodologies for an in situ characterisation have been applied to a model pharmaceutical formulation in order to investigate the effect of HPMC on the formation kinetics and final structure of formulated MET particles during droplet evaporation. The reduced molecular diffusion of HPMC compared with MET and MAN leads to a radial composition profile with increasing polymer-solute ratios towards the droplet surface that in turn lower solvent evaporation. This has implications for drying kinetic models that assume pure liquid evaporation prior to reaching LP. Specifically, particle formation kinetics are delayed with HPMC additions despite higher absolute solute starting concentrations.

For the MET system, XRT analysis shows a negative correlation between HPMC concentration and particle porosity, with the total normalised void space decreasing by $83.59 \%$ between 0 and 10.71 wt\% HPMC. Near spherical and highly buckled particles are produced. The quantification of detected concave surface volumes revealed competing effects of HPMC with an impact on the particle surface. Low concentrations of HPMC lead to smoother surfaces compared to particles without the addition of polymer. For higher HPMC levels, significant particle surface buckling is observed and quantified. The surface buckling itself may not only be related to the kinetics of the solid phase formation at LP but, furthermore, to molecular interactions that cause a partial suppression of the crystalline core. This change in the particle microstructure, its porosity, surface area and surface topology can potentially effect powder flow, compaction behaviour, dissolution and aerodynamic performance of the material.

Advanced models capable to fully describe the complex particle formation mechanisms from solution and their dynamics need to be able to connect molecular interactions and changing spatial compositions to the emerging solid phase structures during processing. Quantitative information from an experimental assessment of the particle design space can feed into a rational particle design approach for novel pharmaceutical systems targeted towards the control or optimisation of particle properties. The ultimate 
goal of such endeavours is to achieve desirable values for shape, porosity and/or solid phase microstructure that can deliver the optimal performance whether during subsequent downstream processes or upon ultimate delivery to the patient. This work serves as the basis of a workflow for the rapid exploration of particle formation processes. It would be desirable to extend its application towards investigating additional formulations and their impact on the final particle structure. Coupled with effective means of performance evaluation, this approach could provide an accelerated design tool for formulated particle systems and processes.

\section{Acknowledgement}

The authors would like to thank EPSRC and the Doctoral Training Centre in Continuous Manufacturing and Crystallisation (Grant Ref: EP/K503289/1) and the EPSRC Future Continuous Manufacturing and Advanced Crystallisation Research Hub (Grant Ref EP/P006965/1) for funding this work. Iain D. H. Oswald would like to thank EPSRC for their funding (Grant Ref: EP/N015401/1). The authors would like to acknowledge that this work was carried out in the CMAC National Facility supported by UKRPIF (UK Research Partnership Fund) award from the Higher Education Funding Council for England (HEFCE) (Grant ref HH13054). All data underpinning this publication are openly available from the University of Strathclyde KnowledgeBase at http://dx.doi.org/XX.XXXXX.

\section{References}

[1] K. Masters, Spray Drying Handbook George Godwin, London, England (1985) 67.

[2] D. E. Walton, C. J. Mumford, Spray Dried Products—Characterization of Particle Morphology, Chemical Engineering Research and Design 77 (1) (1999) 21-38. doi:10.1205/026387699525846

[3] R. Vehring, Pharmaceutical particle engineering via spray drying, Pharmaceutical Research 25 (5) (2008) 999-1022. doi:10.1007/s11095-007-9475-1

[4] A. B. D. Nandiyanto, K. Okuyama, Progress in developing spray-drying methods for the production of controlled morphology particles: from the nanometer to submicrometer size ranges. Advanced Powder Technology 22 (1) (2011) 
$1-19$.

URL https://www.sciencedirect.com/science/article/pii/S0921883110001883?via\{\%\}3Dihub

[5] F. Lyu, J. J. Liu, Y. Zhang, X. Z. Wang, Combined control of morphology and polymorph in spray drying of mannitol for dry powder inhalation. Journal of Crystal Growth 467 (2017) 155-161. doi:10.1016/j.jcrysgro. 2017.03.033. URL http://dx.doi.org/10.1016/j.jcrysgro.2017.03.033

[6] M. I. U. Islam, T. A. G. Langrish, An investigation into lactose crystallization under high temperature conditions during spray drying, Food Research International 43 (1) (2010) 46-56. doi:10.1016/j.foodres .2009.08.010

[7] I.-H. Beak, M.-S. Kim, Improved Supersaturation and Oral Absorption of Dutasteride by Amorphous Solid Dispersions. Chemical and Pharmaceutical Bulletin 60 (11) (2012) 1468-1473. doi:10.1248/cpb.c12-00563. URL http://japanlinkcenter.org/DN/JST.JSTAGE/cpb/c12-00563?lang=en $\{\&\}$ from= CrossRef $\{\&\}$ type=abstract

[8] A. Paudel, Z. A. Worku, J. Meeus, S. Guns, G. van den Mooter, Manufacturing of solid dispersions of poorly water soluble drugs by spray drying: formulation and process considerations, International Journal of Pharmaceutics 453 (1) (2013) 253-284.

[9] S. P. Patil, S. R. Modi, A. K. Bansal, Generation of 1:1 Carbamazepine:Nicotinamide cocrystals by spray drying. European Journal of Pharmaceutical Sciences 62 (2014) 251-257. doi:10.1016/j . ejps .2014.06.001 URL http://dx.doi.org/10.1016/j.ejps.2014.06.001

[10] A. Singh, G. van den Mooter, Spray drying formulation of amorphous solid dispersions, Advanced drug delivery reviews 100 (2016) 27-50. doi:10.1016/j.addr.2015.12.010

[11] V. Vanhoorne, P. J. Van Bockstal, B. Van Snick, E. Peeters, T. Monteyne, P. Gomes, T. De Beer, J. P. Remon, C. Vervaet, Continuous manufacturing of delta mannitol by cospray drying with PVP International Journal of Pharmaceutics 501 (1-2) (2016) 139-147. doi:10.1016/j.ijpharm.2016.02.001 URL http://dx.doi.org/10.1016/j.ijpharm.2016.02.001

[12] R. A. Halliwell, R. M. Bhardwaj, C. J. Brown, N. E. Briggs, J. Dunn, J. Robertson, A. Nordon, A. J. Florence, Spray Drying as a Reliable Route to Produce Metastable Carbamazepine Form IV Journal of Pharmaceutical Sciences 106 (7) (2017) 1874-1880. doi:10.1016/j.xphs.2017.03.045 URL http://dx.doi.org/10.1016/j.xphs.2017.03.045

[13] S. Byrn, M. Futran, H. Thomas, E. Jayjock, N. Maron, R. F. Meyer, A. S. Myerson, M. P. Thien, B. L. Trout, Achieving continuous manufacturing for final dosage formation: Challenges and how to meet them May 20-21, 2014 continuous manufacturing symposium, Journal of Pharmaceutical Sciences 104 (3) (2015) 792-802. doi:10.1002/jps . 24247.

[14] N. Fu, M. W. Woo, C. Selomulya, X. D. Chen, Shrinkage behaviour of skim milk droplets during air drying, Journal of Food Engineering 116 (1) (2013) 37-44. doi:10.1016/j.jfoodeng.2012.11.005

[15] F. Parisse, C. Allain, Drying of Colloidal Suspension Droplets: Experimental Study and Profile Renormalization, Langmuir 13 (14) (1997) 3598-3602. doi:10.1021/la951521g 
[16] T. T. H. Tran, J. G. Avila-Acevedo, E. Tsotsas, Enhanced methods for experimental investigation of single droplet drying kinetics and application to lactose/water, Drying Technology 34 (10) (2016) 1185-1195. doi:10.1080/ 07373937.2015 .1100202

[17] A. Osman, L. Goehring, A. Patti, H. Stitt, N. Shokri, Fundamental Investigation of the Drying of Solid Suspensions, Industrial and Engineering Chemistry Research 56 (37) (2017) 10506-10513. doi:10.1021/acs.iecr.7b02334.

[18] M. Nuzzo, A. Millqvist-Fureby, J. Sloth, B. Bergenstahl, Surface Composition and Morphology of Particles Dried Individually and by Spray Drying Drying Technology 33 (6) (2015) 757-767. doi:10.1080/07373937.2014. 990566

URL http://www.tandfonline.com/doi/abs/10.1080/07373937.2014.990566

[19] E. M. Both, A. M. Karlina, R. M. Boom, M. A. Schutyser, Morphology development during sessile single droplet drying of mixed maltodextrin and whey protein solutions Food Hydrocolloids 75 (2017) 202-210. doi:10.1016/j. foodhyd.2017.08.022 URL https://doi.org/10.1016/j.foodhyd.2017.08.022

[20] J. Sloth, S. Kiil, A. D. Jensen, S. K. Andersen, K. Jørgensen, H. Schiffter, G. Lee, Model based analysis of the drying of a single solution droplet in an ultrasonic levitator, Chemical Engineering Science 61 (8) (2006) 2701-2709. doi: $10.1016 / \mathrm{j} \cdot \mathrm{ces} .2005 .11 .051$

[21] J. K. R. Weber, C. A. Rey, J. Neuefeind, C. J. Benmore, Acoustic levitator for structure measurements on low temperature liquid droplets, Review of Scientific Instruments 80 (8) (2009) 1-8. doi:10.1063/1.3196177

[22] T. Ullum, J. Sloth, a. Brask, M. Wahlberg, Predicting Spray Dryer Deposits by CFD and an Empirical Drying Model. Drying Technology 28 (5) (2010) 723-729. doi:10.1080/07373931003799319 URL http://www.tandfonline.com/doi/abs/10.1080/07373931003799319

[23] J. K. R. Weber, C. J. Benmore, A. N. Tailor, S. K. Tumber, J. Neuefeind, B. Cherry, J. L. Yarger, Q. Mou, W. Weber, S. R. Byrn, A neutron-X-ray, NMR and calorimetric study of glassy Probucol synthesized using containerless techniques. Chemical Physics 424 (2013) 89-92. doi:10.1016/j.chemphys.2013.05.019. URL http://dx.doi.org/10.1016/j.chemphys.2013.05.019

[24] C. J. Benmore, J. Weber, A. N. Tailor, B. R. Cherry, J. L. Yarger, Q. Mou, W. Weber, J. Neuefeind, S. R. Byrn, Structural Characterization and Aging of Glassy Pharmaceuticals made Using Acoustic Levitation Journal of Pharmaceutical Sciences 102 (4) (2013) 1290-1300. doi:10.1002/jps.23464 URL http://linkinghub.elsevier.com/retrieve/pii/S0022354915311461

[25] M. Griesing, H. Grosshans, T. Hellwig, R. Sedelmayer, S. Gopireddy, W. Pauer, E. Gutheil, H.-U. Moritz, Influence of the Drying Air Humidity on the Particle Formation of Single Mannitol-Water Droplets, Chemie-Ingenieur-Technik submitted (7) (2015) 1-9. doi:10.1002/cite.201500087

[26] M. Kreimer, I. Aigner, S. Sacher, M. Krumme, T. Mannschott, P. van der Wel, A. Kaptein, H. Schroettner, G. Brenn, J. G. Khinast, Mechanical strength of microspheres produced by drying of acoustically levitated suspension droplets. Powder Technology 325 (2018) 247-260. doi:10.1016/j.powtec.2017.11.013 URL https://doi.org/10.1016/j . powtec. 2017.11 .013 
[27] S. I. F. Badawy, D. B. Gray, M. A. Hussain, A study on the effect of wet granulation on microcrystalline cellulose particle structure and performance, Pharmaceutical Research 23 (3) (2006) 634-640. doi:10.1007/ s11095-005-9555-z

[28] B. Barot, P. Parejiya, T. Patel, R. Parikh, M. Gohel, Development of directly compressible metformin hydrochloride by the spray-drying technique Acta Pharmaceutica 60 (2) (2010) 165-175. doi:10.2478/v10007-010-0016-9 URL http://www.degruyter.com/view/j/acph.2010.60.issue-2/v10007-010-0016-9/ v10007-010-0016-9.xml

[29] N. Rasenack, H. Hartenhauer, B. W. Müller, Microcrystals for dissolution rate enhancement of poorly water-soluble drugs, International Journal of Pharmaceutics 254 (2) (2003) 137-145. doi:10.1016/S0378-5173(03)00005-X

[30] G. Perfetti, E. V. D. Casteele, B. Rieger, W. J. Wildeboer, G. M. H. Meesters, X-ray micro tomography and image analysis as complementary methods for morphological characterization and coating thickness measurement of coated particles Advanced Powder Technology 21 (6) (2010) 663-675. doi:10.1016/j.apt.2010.08.002 URL http://dx.doi.org/10.1016/j.apt.2010.08.002

[31] P. Trtik, M. Soos, B. Munch, A. Lamprou, R. Mokso, M. Stampanoni, Quantification of a single aggregate inner porosity and pore accessibility using hard X-ray phase-contrast nanotomography, Langmuir : the ACS journal of surfaces and colloids 27 (21) (2011) 12788-12791. doi:10.1021/la203432v

[32] F. Sondej, A. Bück, K. Koslowsky, P. Bachmann, M. Jacob, E. Tsotsas, Investigation of coating layer morphology by micro-computed X-ray tomography Powder Technology 273 (2015) 165-175. doi:10.1016/j ·powtec.2014.12. 050 URL http://dx.doi.org/10.1016/j.powtec.2014.12.050

[33] R. Tuckermann, S. Bauerecker, H. K. Cammenga, IR-Thermography of Evaporating Acoustically Levitated Drops. International Journal of Thermophysics 26 (5) (2005) 1583-1594. doi:10.1007/s10765-005-8105-6 URL http://dx.doi.org/10.1007/s10765-005-8105-6

[34] World Health Organization, WHO Model List of Essential Medicines - 19th List (April 2015) Essential Medicines (April) (2015) 1-45. arXiv: NIHMS150003 doi:10.1016/S1473-3099(14)70780-7 URL http://www. who.int/medicines/publications/pharmacopoeia.

[35] G. Corti, M. Cirri, F. Maestrelli, N. Mennini, P. Mura, Sustained-release matrix tablets of metformin hydrochloride in combination with triacetyl- $\beta$-cyclodextrin, European Journal of Pharmaceutics and Biopharmaceutics 68 (2) (2008) 303-309. doi:10.1016/j.ejpb.2007.06.004

[36] L. C. Block, L. O. Schemling, A. G. Couto, S. C. Mourão, T. M. B. Bresolin, Pharmaceutical equivalence of metformin tablets with various binders, Revista de Ciencias Farmaceuticas Basica e Aplicada 29 (1) (2008) 29-35

[37] B. S. Barot, P. B. Parejiya, T. M. Patel, R. K. Parikh, M. C. Gohel, Compactibility improvement of metformin hydrochloride by crystallization technique Advanced Powder Technology 23 (6) (2012) 814-823. doi:10.1016/j. apt.2011.11.002

URL http://dx.doi.org/10.1016/j.apt.2011.11.002 
[38] V. Mokale, R. Rajput, J. Patil, S. Yadava, J. Naik, Formulation of metformin hydrochloride nanoparticles by using spray drying technique and in vitro evaluation of sustained release with 32-level factorial design approach Drying Technology 34 (12) (2016) 1455-1461. doi:10.1080/07373937.2015.1125916

URL http://dx.doi.org/10.1080/07373937.2015.1125916

[39] R. Hamed, A. Al-Samydai, T. Al Baraghthi, O. Tarawneh, S. Sunoqrot, Influence of HPMC K100LV and Compritol® HD5 ATO on Drug Release and Rheological Behavior of HPMC K4M Matrix Tablets, Journal of Pharmaceutical Innovation 12 (1) (2017) 62-75. doi:10.1007/s12247-016-9269-2

[40] P. Perona, J. Malik, Scale-space and edge detection using anisotropic diffusion IEEE Transactions on Pattern Analysis and Machine Intelligence 12 (7) (1990) 629-639. arXiv:1102.0183 doi:10.1109/34.56205 URL http://ieeexplore.ieee.org/lpdocs/epic03/wrapper.htm?arnumber=56205

[41] G. Gerig, O. Kubler, R. Kikinis, F. a. Jolesz, Nonlinear anisotrophic filtering of MRI data, IEEE Transactions on Medical Imaging 11 (2) (1992) 221-232.

[42] S. Ridler, T.W. Calvard, Picture Thresholding Using an Iterative Slection Method, IEEE Transactions on Systems, Man and Cybernetics 8 (8) (1978) 630-632. doi:10.1109/TSMC.1978.4310039

[43] C. B. Barber, D. P. Dobkin, H. Huhdanpaa, The quickhull algorithm for convex hulls ACM Transactions on Mathematical Software 22 (4) (1996) 469-483. arXiv:arXiv:1011.1669v3 doi:10.1145/235815.235821 URL http://portal .acm.org/citation. cfm?doid=235815.235821

[44] A. Muginstein, M. Fichman, C. Gutfinger, Gas absorption in a moving drop containing suspended solids, International Journal of Multiphase Flow 27 (6) (2001) 1079-1094. doi:10.1016/S0301-9322(00)00063-X.

[45] R. Vehring, Pharmaceutical particle engineering via spray drying, Pharmaceutical research 25 (5) (2008) 999-1022.

[46] R. Rowe, P. Sheskey, M. Quinn, Handbook of Pharmaceutical Excipients, Handbook of pharmaceutical excipients, Sixth edition (2009) 549-55: arXiv: arXiv: 1011.1669v3 doi:10.1016/S0168-3659(01) 00243-7

[47] T. Toshihiro, M. Shigetoshi, Diffusion of polar and nonpolar molecules in water and ethanol Bulletin of the Chemical Society of Japan 63 (2) (1990) 533-537. doi:10.1246/bcsj.63.533 URL http://www.journal.csj.jp/doi/abs/10.1246/bcsj.63.533

[48] R. Callendar, D. G. Leaist, Diffusion coefficients for binary, ternary, and polydisperse solutions from peak-width analysis of Taylor dispersion profiles, Journal of Solution Chemistry 35 (3) (2006) 353-379. doi:10.1007/ s10953-005-9000-2

[49] D. Desai, B. Wong, Y. Huang, Q. Ye, D. Tang, H. Guo, M. Huang, P. Timmins, Surfactant-mediated dissolution of metformin hydrochloride tablets: Wetting effects versus ion pairs diffusivity Journal of Pharmaceutical Sciences 103 (3) (2014) 920-926. doi:10.1002/jps.23852 URL http://dx.doi.org/10.1002/jps.23852

[50] N. S. Trasi, K. A. Oucherif, J. D. Litster, L. S. Taylor, Evaluating the influence of polymers on nucleation and growth in supersaturated solutions of acetaminophen, CrystEngComm (2015) 1242-124\&doi:10.1039/c4ce02179g 
[51] E. M. Littringer, R. Paus, A. Mescher, H. Schroettner, P. Walzel, N. A. Urbanetz, The morphology of spray dried mannitol particles - The vital importance of droplet size Powder Technology 239 (2013) 162-174. doi:10.1016/ j.powtec.2013.01.065 URL http://dx.doi.org/10.1016/j.powtec.2013.01.065

[52] S. Shakiba, S. Mansouri, C. Selomulya, M. W. Woo, In-situ crystallization of particles in a counter-current spray dryer. Advanced Powder Technology 27 (6) (2016) 2299-2307. doi:10.1016/j . apt.2016.07.001. URL http://dx.doi.org/10.1016/j.apt.2016.07.001

[53] H. Wadell, Volume, Shape, and Roundness of Quartz Particles. The Journal of Geology 43 (3) (1935) 250-280. doi: $10.1086 / 624298$

URL https://doi.org/10.1086/624298 


\section{Figures}
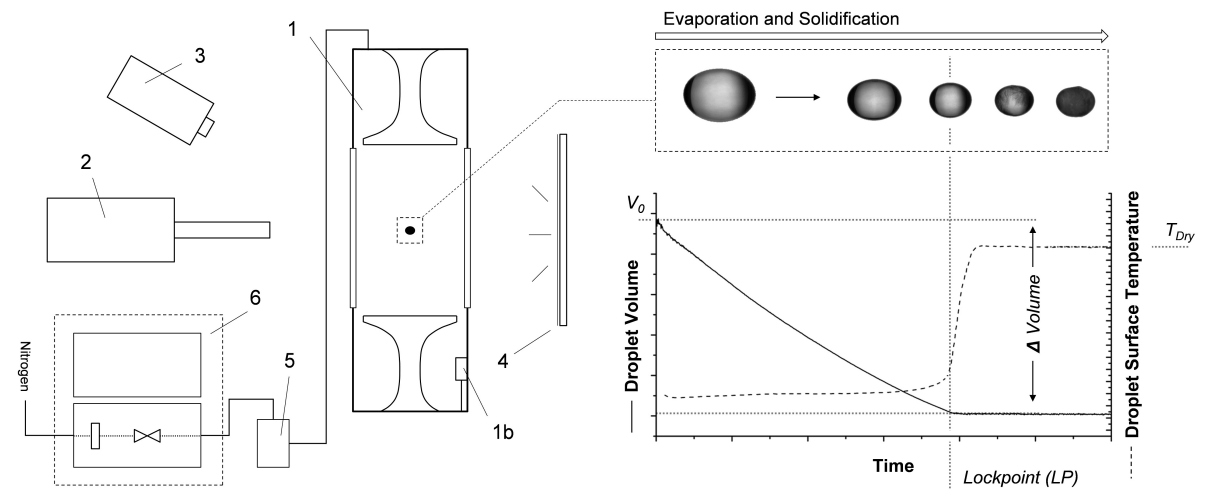

Figure 1: (Left) Experimental Setup with (1) acoustic levitator with two opposed transducers and an enclosure with (1b) a sensor for measuring temperature and relative humidity. The evaporation process is monitored using (2) a high speed - and (3) thermal imaging systems. The droplets are back-illuminated with (4) an LED light source plus diffuser. Nitrogen is filtered heated and the flow is regulated with a system from Okalab (5 - 6). (Right) Image analysis allows the extraction of information on the droplet volume and surface temperature for the course of the evaporation process to detect initial solid skin formation (Lockpoint, LP) and reaching a state with constant end temperature $\left(T_{D r y}\right)$. 


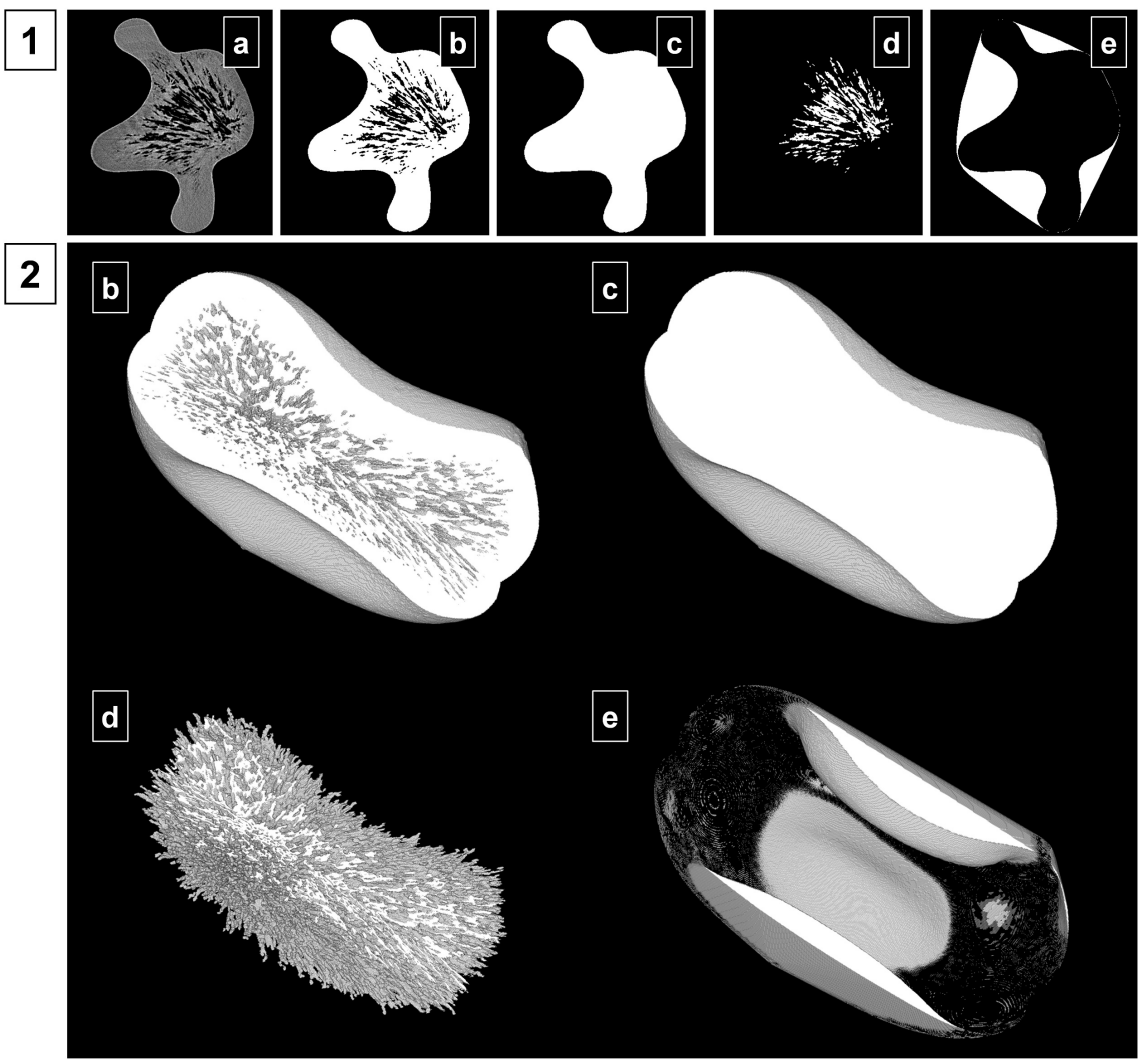

Figure 2: XRT image processing to extract quantitative descriptors for particle size, shape, porosity and surface buckling. (1) Selected single 2D cross-section images and (2) volume-rendered 3D image stacks with insections. (a) Grayscale images after reconstruction, (b) binarised images after thresholding and noise reduction (V), (c) region of interest for primary particle volume (V_ROI), (d) particle porosity $\left(\Delta \mathrm{V} \_\mathrm{ROI}\right)$ and (e) particle concave volume ( $\Delta$ V_ROI_CH). 


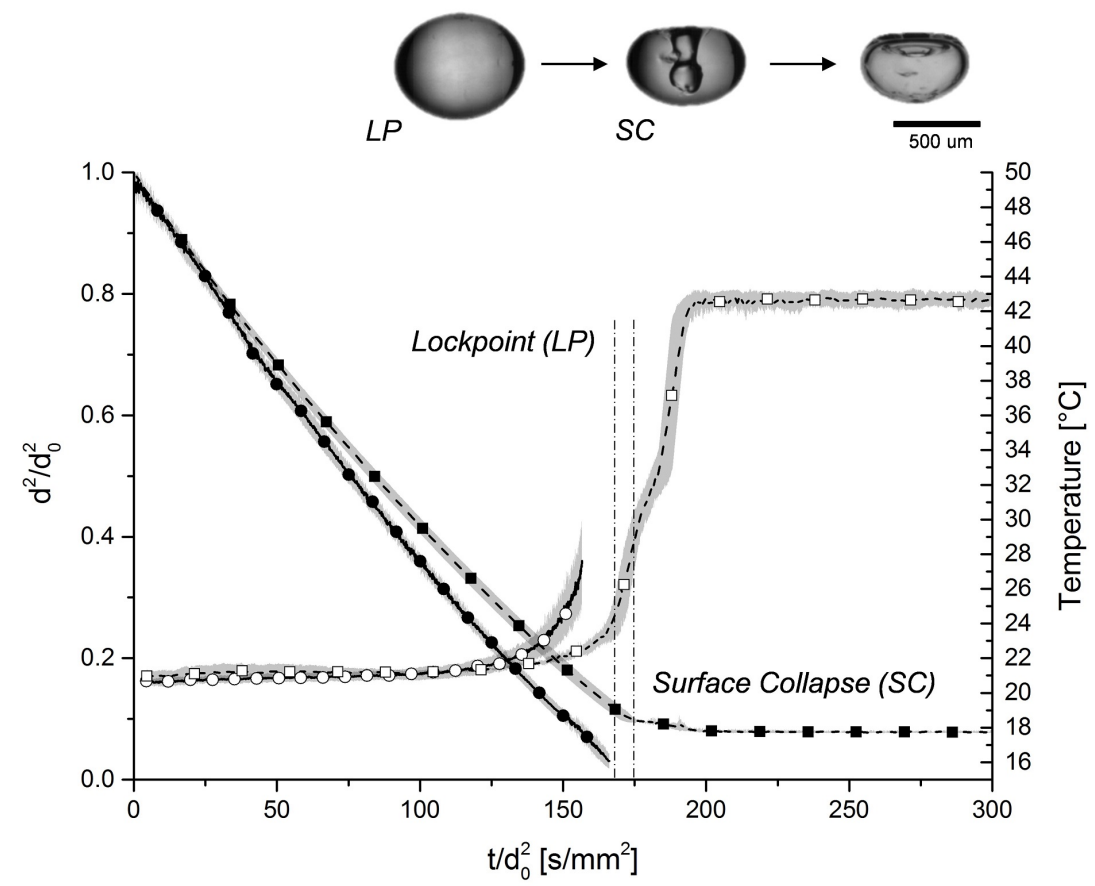

Figure 3: Drying curves for ( $-\mathbf{D}$-) de-ionized water and ( -- --$)$ aqueous HPMC solution (HPMC_10, $c_{0} 10 \mathrm{mg} / \mathrm{mL}$ ). The data show an increasing deviation of the evaporation kinetics for HPMC_10 compared to pure water over time and prior to the detection of skin formation (LP). After LP, the particle surface collapses (SC) before reaching an ambient end-temperature level resulting in a two-step transition mechanism. Black symbols - normalised squared diameter, white symbols - surface temperature. Data from replicates with $\mathrm{n} \geq 3$. 


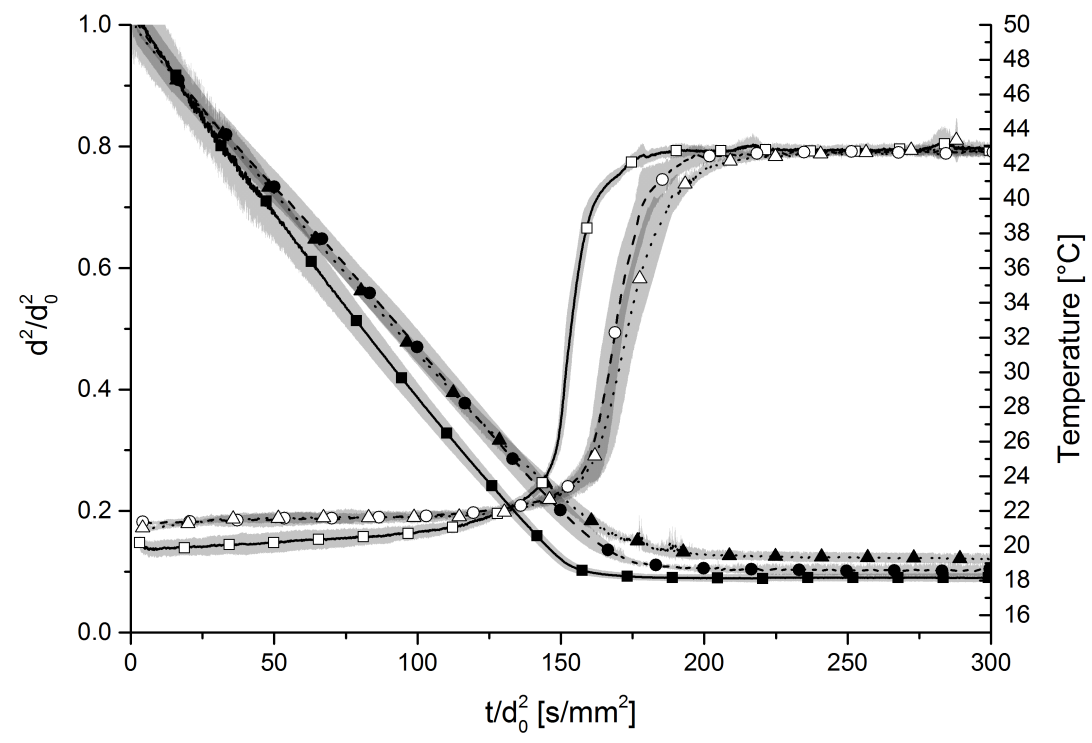

Figure 4: Drying curves for formulations of MET and MAN with equal starting concentrations of $18.75 \mathrm{mg} / \mathrm{mL}$ and increasing additions of HPMC: ( - $\mathbf{-}$ ) MS_0, $c_{0} 0 \mathrm{mg} / \mathrm{mL},\left(--\mathbf{D}^{--}\right) \mathrm{MS} \_1, c_{0} 0.375 \mathrm{mg} / \mathrm{mL}$ and $(\cdots \Delta \cdots)$ MS $\_4, c_{0} 4.5 \mathrm{mg} / \mathrm{mL}$. MS_0 without HPMC exhibits significantly higher evaporation kinetics compared to MS_1 and MS_4. Black symbols - normalised squared diameter, white symbols - surface temperature. Data from replicates with $n \geq 5$. 

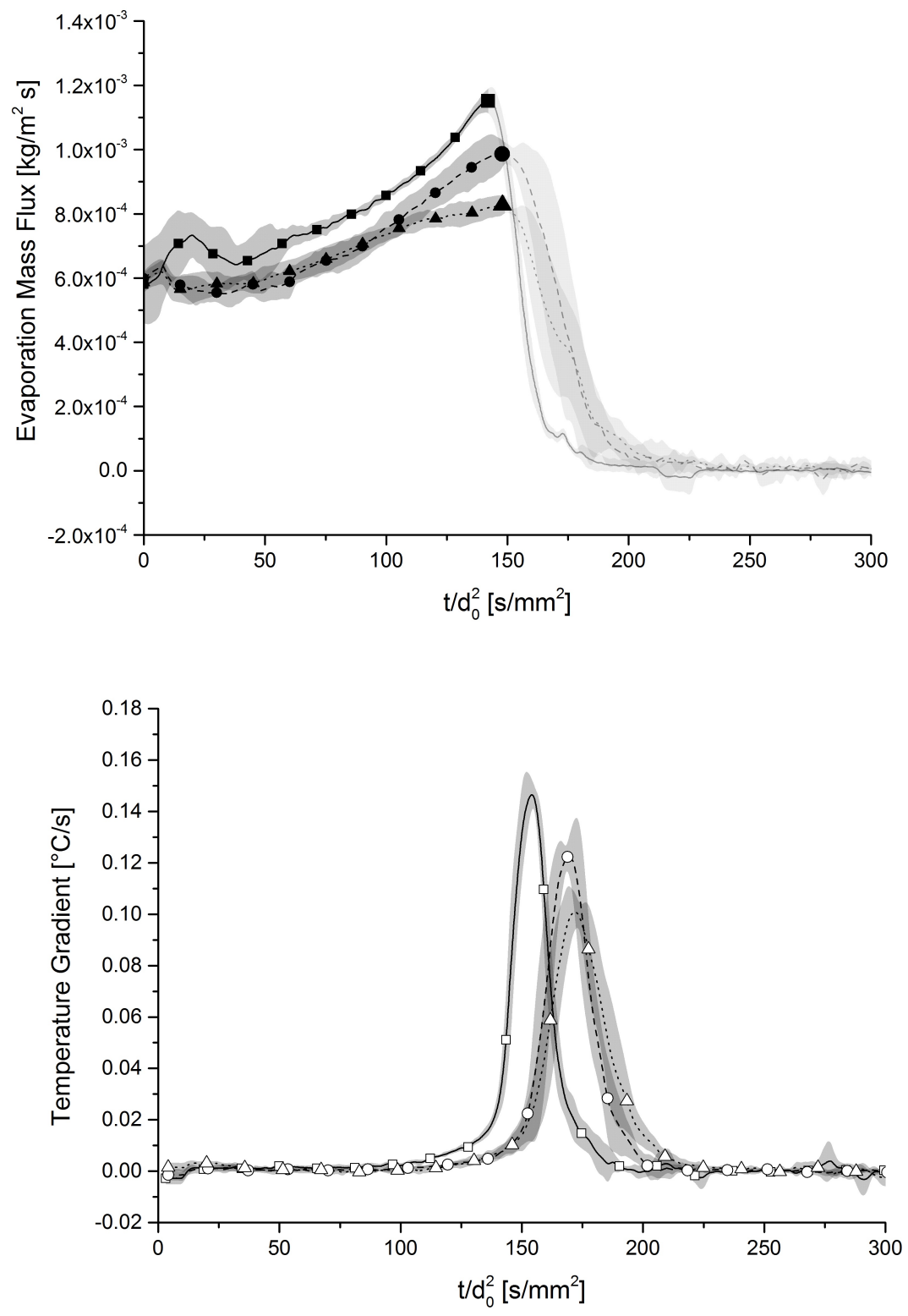

Figure 5: Solidification kinetics of formulation of MET and MAN with equal starting concentrations of $18.75 \mathrm{mg} / \mathrm{mL}$ and varying additions of HPMC: ( - $\mathbf{-}-)$ MS_0, $c_{0}$ $0 \mathrm{mg} / \mathrm{mL},\left(--\mathbf{D}^{--}\right)$MS_1,$c_{0} 0.375 \mathrm{mg} / \mathrm{mL}$ and $\left(\cdots \triangle^{\cdots}\right)$ MS_4 $c_{0} 4.5 \mathrm{mg} / \mathrm{mL}$. The evaporation flux increases over time and is significantly lower for droplets with added HPMC. The drying kinetics are reduced with increasing HPMC concentrations. Black symbols - evaporation mass flux, white syæ6ols - surface heating rate. Data from replicates with $\mathrm{n} \geq 5$. 


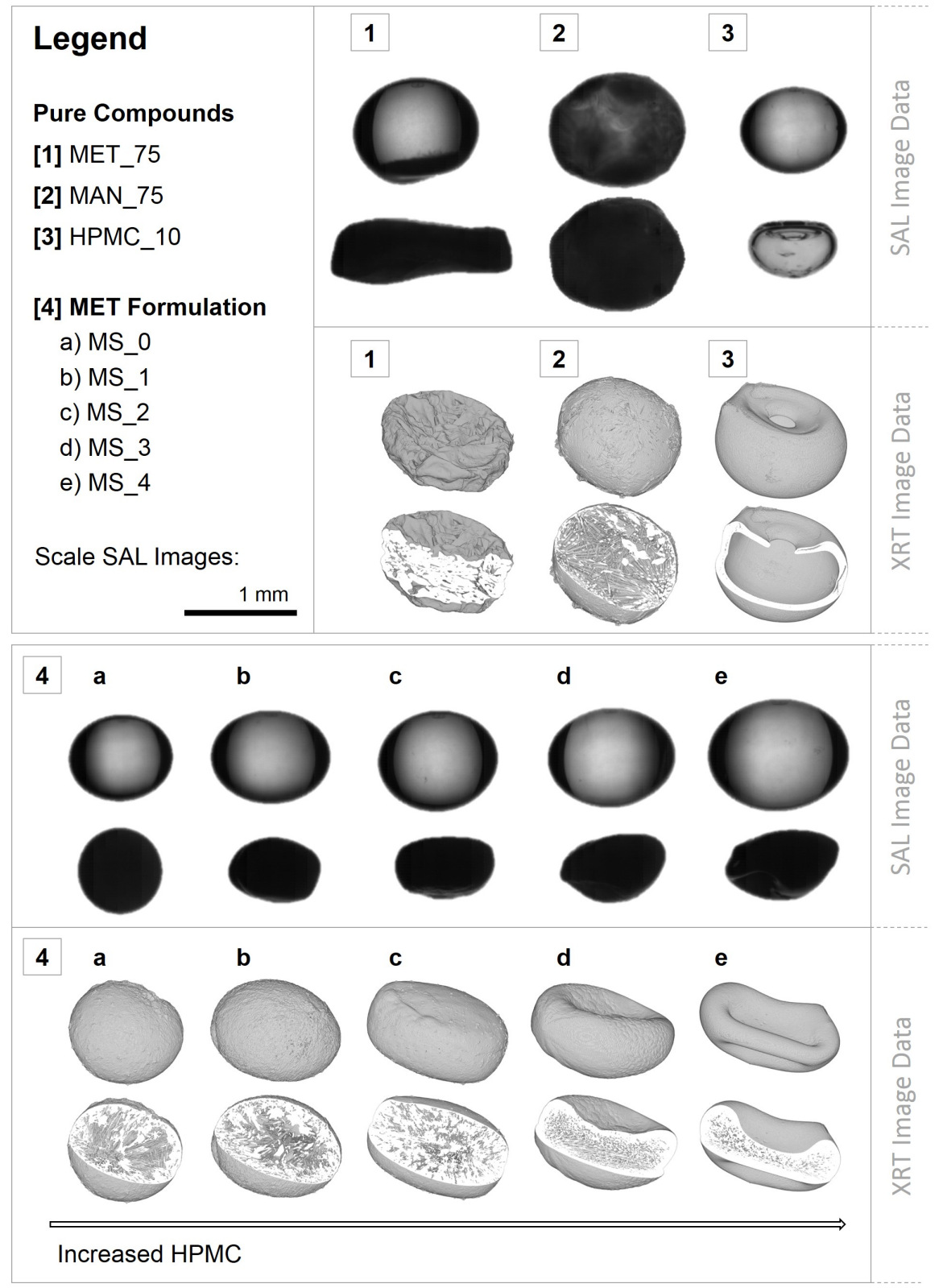

Figure 6: Visualisation of the investigated particle design space for solids obtained from single droplet evaporation experiments (SAL Image Data) and after XRT characterisation (XRT Image Data). The individual compounds (1-3) show distinct particle characteristics with an impact on the particle morphology for tested formulations of MET (MS_0 - MS_4, 4 a-e). 
a

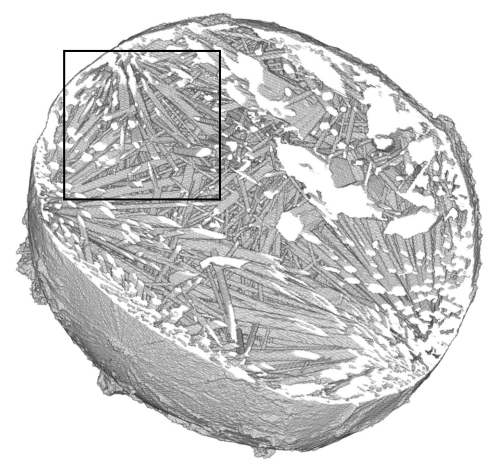

b

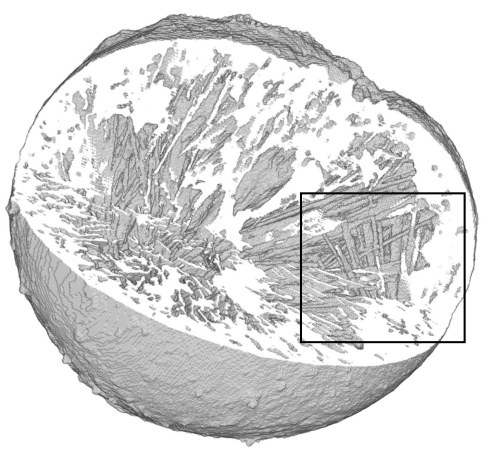

C

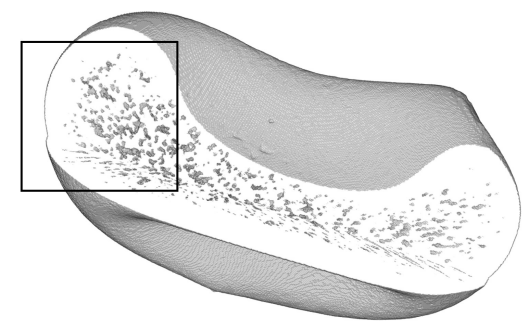

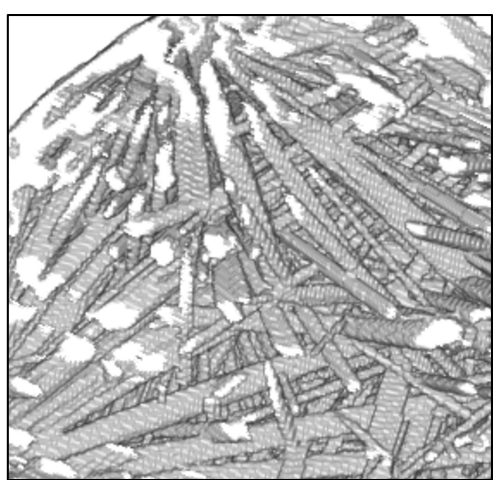
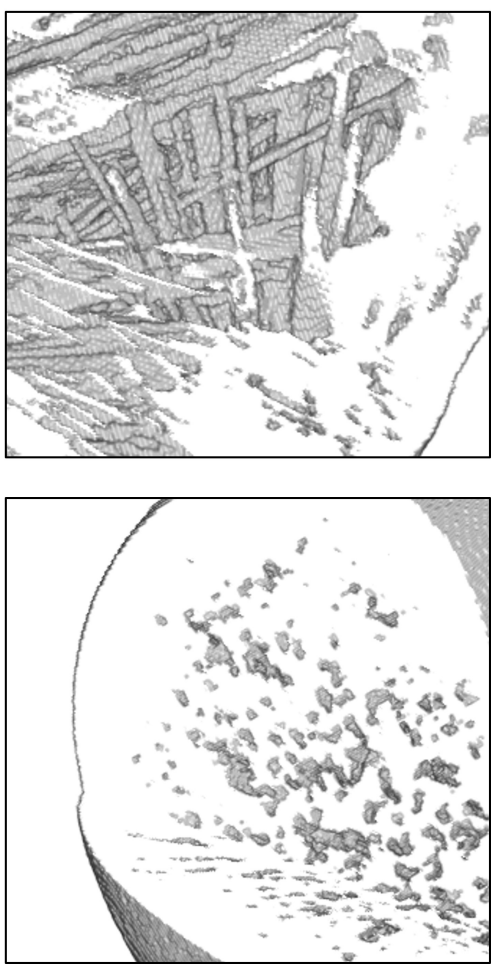

Figure 7: XRT reveals the internal structure and morphology of particles collected from single droplet evaporation experiments of (a) pure MAN solution (MAN_75), (b) MET formulation without HPMC (MS_0) and (c) MET formulation with $10.71 \mathrm{wt} \%$ HPMC (MS_4). The cores of particles from MAN_75 solution are dominated by rod-shaped primary crystalline solids. For formulated particles, the extent and the size of these primary crystalline solids are significantly suppressed with increasing polymer solid mass ratios. 

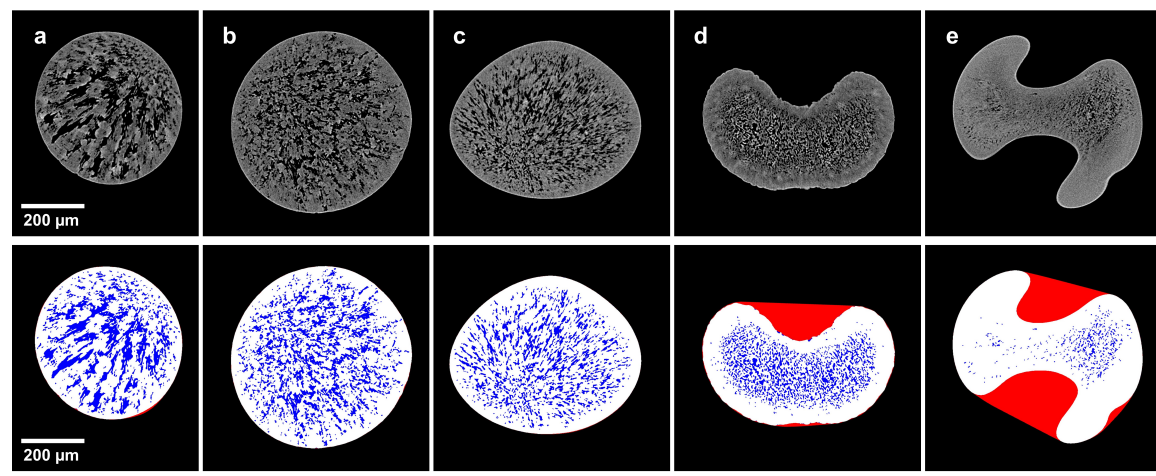

Figure 8: Selected 2D cross-sections (top - grayscale, bottom - binarised) of formulated MET particles with MAN and increasing additions of HPMC: (a) MS_0, (b) MS_1, (c) MS $\_$, (d) MS_3, (e) MS_4). The images show the detected particle volume (white), porosity (blue) and concave surface volume (red) for the presented cross-sections after binarisation. 


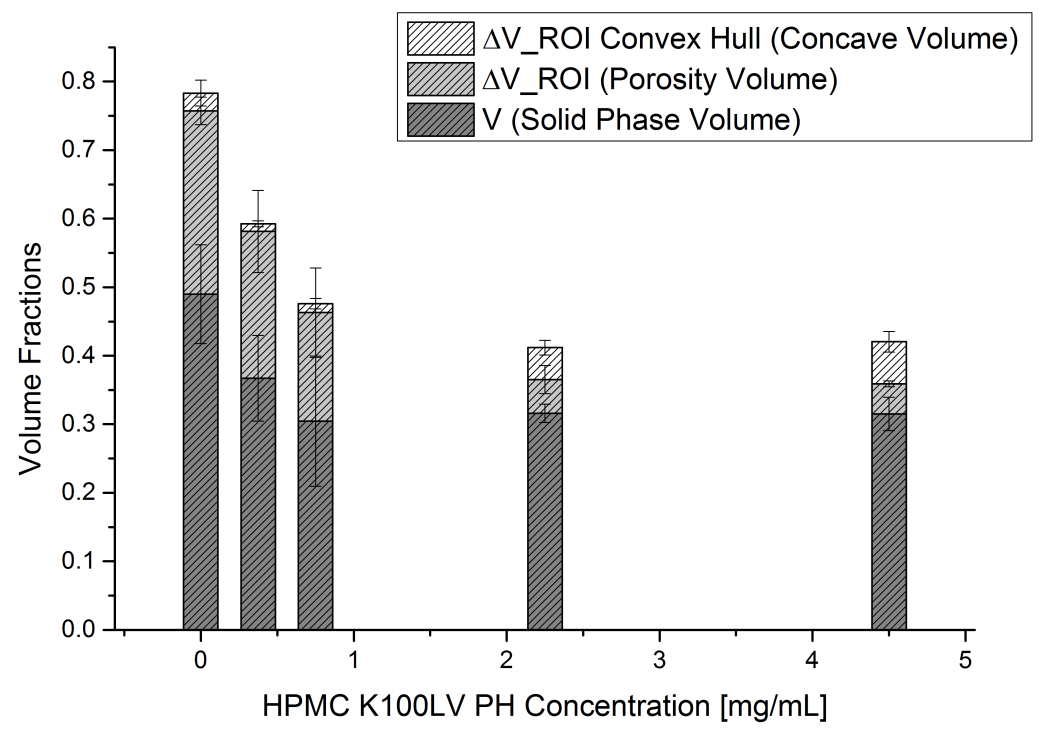

Figure 9: Ratios of particle solid phase volume (V), particle porosity volume $\left(\Delta \mathrm{V} \_\mathrm{ROI}\right)$, and particle concave volume $\left(\Delta \mathrm{V} \_\right.$ROI Convex Hull) for MS_0 - MS_4. All volumes are normalised to the volume of a sphere with equivalent maximum Feret diameter $\left(\mathrm{V}_{\text {eqSph,Feret }}\right)$. 


\section{Tables}

Table 1: Preparation schemata for solutions of metformin hydrochloride, D-mannitol and Benecel K100LV PH PRM with sample ID and starting concentrations $\left(c_{0}\right)$.

\begin{tabular}{|l|l|l|l|}
\hline Sample & $\begin{array}{l}c_{0, M E T} \\
{[\mathrm{mg} / \mathrm{mL}]}\end{array}$ & $\begin{array}{l}c_{0, M A N} \\
{[\mathrm{mg} / \mathrm{mL}]}\end{array}$ & $\begin{array}{l}c_{0, H P M C} \\
{[\mathrm{mg} / \mathrm{mL}]}\end{array}$ \\
\hline \hline MET_75 & 75 & - & - \\
\hline MAN_75 & - & 75 & - \\
\hline HPMC_10 & - & - & 10 \\
\hline MS_0 & 18.75 & 18.75 & - \\
\hline MS_1 & 18.75 & 18.75 & 0.375 \\
\hline MS_2 & 18.75 & 18.75 & 0.750 \\
\hline MS_3 & 18.75 & 18.75 & 2.250 \\
\hline MS_4 & 18.75 & 18.75 & 4.500 \\
\hline
\end{tabular}

Table 2: Calculated density of HPMC and its molecular diffusion coefficient in water based on experimental results from three individual SAL experiments and XRT analysis.

\begin{tabular}{|l|l|l|l|}
\hline HPMC_10 & $m_{0}[\mu \mathrm{g}]$ & $\rho_{\text {crit }}\left[\mathrm{g} / \mathrm{cm}^{3}\right]$ & $D_{s}\left[10^{-11} \mathrm{~m}^{2} / \mathrm{s}\right]$ \\
\hline \hline Exp1 & 92.17 & 1.34 & 4.622 \\
\hline Exp2 & 92.60 & 1.38 & 4.872 \\
\hline Exp3 & 96.97 & 1.38 & 4.343 \\
\hline Mean & & $1.36 \pm 0.02$ & $4.612 \pm 0.264$ \\
\hline
\end{tabular}

Table 3: Maximum mass flux $\left(\dot{m}_{\max }\right)$ and heating rate $\left(\dot{T}_{\max }\right)$ during droplet drying experiments for HPMC (HPMC_10) and five tested MET formulations (MS_0 - MS_4).

\begin{tabular}{|l|l|l|l|}
\hline Sample & $\mathrm{n}$ & $\dot{m}_{\max }\left[10^{-4} \mathrm{~kg} /\left(\mathrm{m}^{2} \cdot \mathrm{s}\right)\right]$ & $\dot{T}_{\max }\left[{ }^{\circ} \mathrm{C} / \mathrm{s}\right]$ \\
\hline \hline HPMC_10 & 3 & $9.89 \pm 0.12$ & $0.113 \pm 0.006$ \\
\hline MS_0 & 6 & $11.62 \pm 0.39$ & $0.148 \pm 0.004$ \\
\hline MS_1 & 8 & $10.12 \pm 0.10$ & $0.135 \pm 0.006$ \\
\hline MS_2 & 5 & $9.96 \pm 0.23$ & $0.131 \pm 0.007$ \\
\hline MS_3 & 3 & $9.18 \pm 0.48$ & $0.123 \pm 0.006$ \\
\hline MS_4 & 6 & $8.36 \pm 0.29$ & $0.106 \pm 0.003$ \\
\hline
\end{tabular}


Table 4: Overview of extracted shape descriptors from formulated MET particle systems MS_0 - MS_4 ( $\mathrm{n}=$ number of particles).

\begin{tabular}{|l|l|l|l|}
\hline Sample & $\mathrm{n}$ & Aspect Ratio & Sphericity \\
\hline \hline MS_0 & 7 & $1.20 \pm 0.05$ & $0.95 \pm 0.04$ \\
\hline MS_1 & 8 & $1.96 \pm 0.52$ & $0.90 \pm 0.05$ \\
\hline MS_2 & 3 & $1.93 \pm 0.28$ & $0.89 \pm 0.05$ \\
\hline MS_3 & 5 & $2.49 \pm 0.35$ & $0.80 \pm 0.05$ \\
\hline MS_4 & 5 & $2.52 \pm 0.20$ & $0.73 \pm 0.03$ \\
\hline
\end{tabular}




\section{Electronic Supplementary Information}

Table 5: Thermal emissivity correction factors for solid phase of HPMC and formulations of MET with MAN and HPMC.

\begin{tabular}{|c|c|}
\hline & $\varepsilon$ \\
\hline \hline HPMC_10 & $0.988 \pm 0.006$ \\
\hline MS_0 & $0.942 \pm 0.012$ \\
\hline MS_1 & $0.929 \pm 0.011$ \\
\hline MS_2 & $0.936 \pm 0.002$ \\
\hline MS_3 & $0.949 \pm 0.013$ \\
\hline MS_4 & $0.932 \pm 0.005$ \\
\hline
\end{tabular}




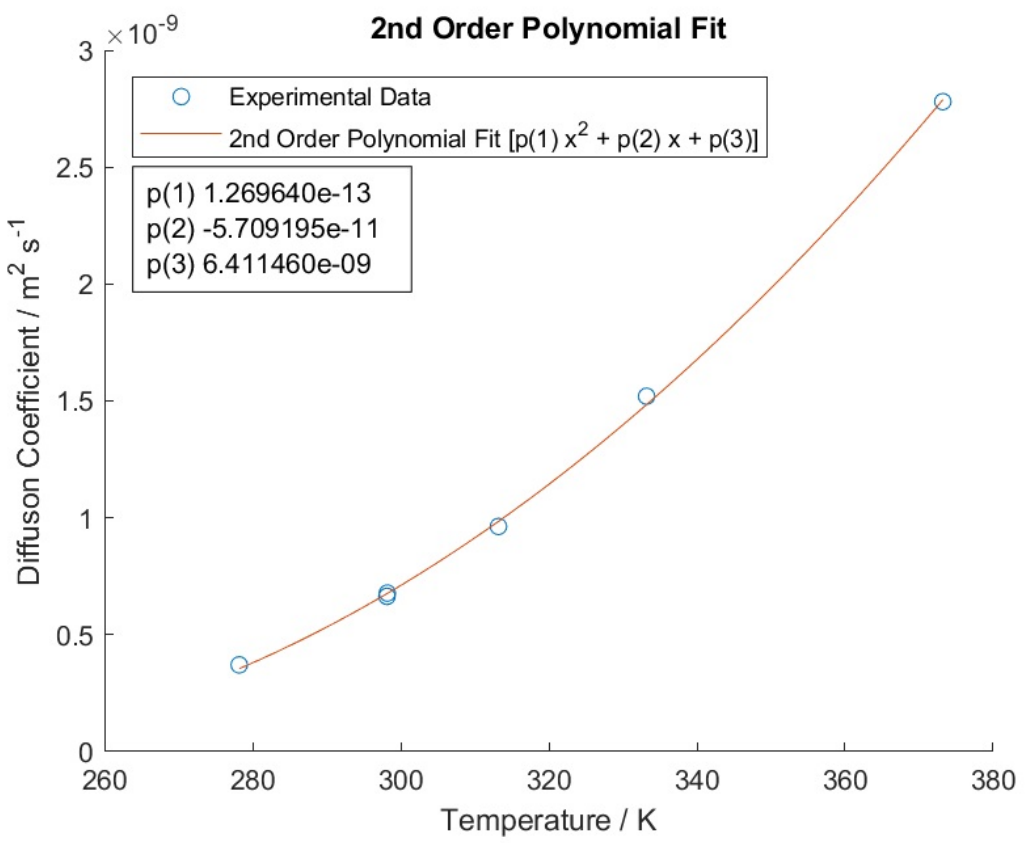

Figure 10: 2nd degree polynomial fit to calculate the diffusion coefficient of MAN in water. Reported experimental data from literature. [47, 48] 